\title{
Redox-Neutral Manganese-Catalyzed Silylation of Alkenes
}
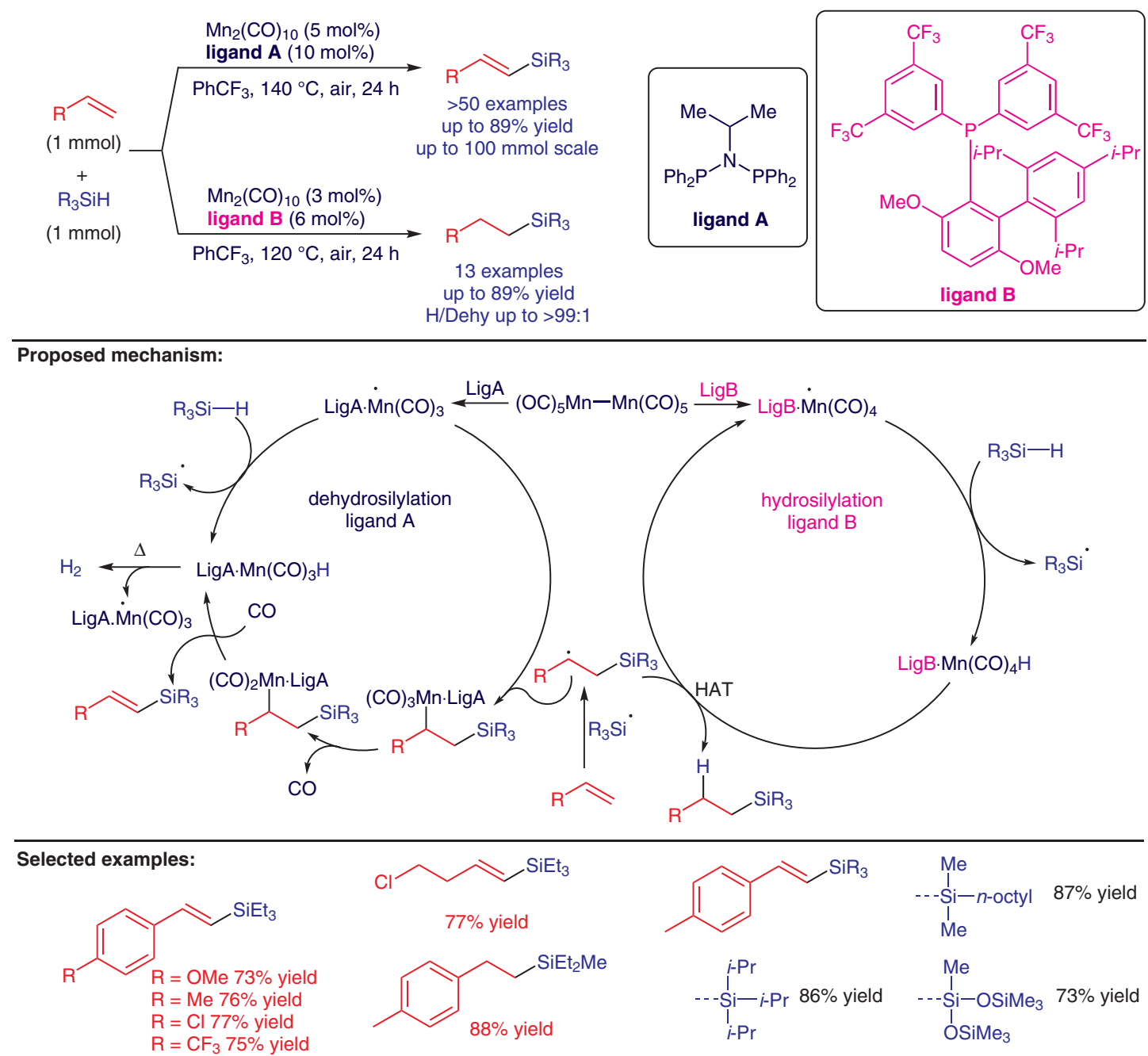

Significance: Xie and co-workers report a manganese-catalyzed dehydrosilylation and hydrosilylation of alkenes. They have shown that the reaction is easily scalable and affords the silylated product in good yields. The reaction proceeds equally well with both aliphatic and aromatic alkene starting materials.
Comment: Notably, the reaction is highly selective for the linear silylated product, stemming from the anti-Markovnikov addition of the silyl radical to the alkene. Additionally, under the specific conditions, either the dehydrosilylation or hydrosilylation product can be accessed with excellent selectivity.

\section{Key words}

manganese catalysis hydrosilylation

dehydrosilylation

redox-neutral reaction

manganese radicals

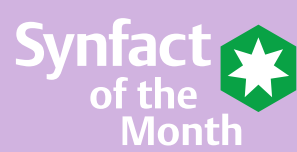

